\title{
Survey on the Amount of Physical Activity and Self-Esteem of School Age Students in A Town in Japan
}

\author{
Ayako Ohgino', Yumiko Nakamura², Kahara Yukie ${ }^{2}$ \\ ${ }^{1}$ Graduate School of Health Sciences, Hirosaki University, Hirosaki, Japan \\ ${ }^{2}$ Department of Nursing, Bunkyo Gakuin University, Tokyo, Japan \\ Email: ohgino@hirosaki-u.ac.jp
}

How to cite this paper: Ohgino, A., Nakamura, Y. and Yukie, K. (2022) Survey on the Amount of Physical Activity and SelfEsteem of School Age Students in A Town in Japan. Health, 14, 46-56.

https://doi.org/10.4236/health.2022.141004

Received: December 20, 2021

Accepted: January 11, 2022

Published: January 14, 2022

Copyright $\odot 2022$ by author(s) and Scientific Research Publishing Inc. This work is licensed under the Creative Commons Attribution International License (CC BY 4.0).

http://creativecommons.org/licenses/by/4.0/

\begin{abstract}
This study aimed to clarify the amount of physical activity, lifestyle, and selfesteem of elementary school students living in Aomori Prefecture Japan. The subjects were ninety-one elementary school students in the 4th to 6th grades who live in A town. The subjects were asked to fill out a questionnaire about lifestyles and self-esteem and to wear the lifestyle-related recorder Life Coder $\mathrm{GS}^{\circledast}$ (Suzuken, Japan) for a total of four days, two weekdays and two holidays. The results showed the amount of exercise such as the number of steps taken was significantly higher on weekdays than on holidays. There was no difference by gender or classification of obesity. In addition, when they go to school on foot, the number of steps and fast walking time was significantly higher than when using the bus. Screen times of holidays were significantly longer than those of weekdays. The number of steps on holidays was negatively correlated with screen time, and positively correlated with the factor of "self-assertion/self-determination" of self-esteem scale. Health promotion is needed so that the entire community, including family and friends, can develop daily physical activities.
\end{abstract}

\section{Keywords}

Physical Activity, Children, Exercise, Self-Esteem

\section{Introduction}

Childhood obesity is a risk factor for lifestyle-related diseases such as type 2 diabetes, hypertension, and non-alcoholic liver dysfunction [1], and it has been 
suggested that childhood healthy lifestyle leads to adulthood health. Not only that, children's obesity and activity are said to be related to psychological aspects such as self-esteem and quality of life.

It is known that the proportion of obese children tends to increase from the latter half of elementary school to junior high school [2]. In addition to the relatively stable period of height growth, multiple factors such as eating habits, exercise habits [3] [4], genetic factors, environmental factors, and psychological factors influence each other [5]. Obesity during this period is also clearly at high risk of exacerbating severe obesity [6] [7]. Therefore, obesity of elementary school children must be prevented as much as possible.

By the way, school-aged children in Aomori Prefecture have a higher rate of obesity than the national average. For example, according to the 2017 School Health Statistics Survey, the national average obesity rate for 9-year-olds is $8.63 \%$, while that for Aomori Prefecture is $12.58 \%$ [8]. In addition, Aomori Prefecture has a shorter life expectancy than the whole country [9], so improving lifestyle habits is an urgent issue. For future health, it is expected that acquiring a health-conscious lifestyle from school age will have a positive effect on longterm physical and mental health and QOL.

It is also said that obese children have low self-esteem [10] due to deterioration of body image and motor function. On the other hand, it has also been suggested that exercise has a positive effect on self-esteem [11] [12].

Therefore, in this study, we surveyed the amount of exercise, living conditions, and self-esteem of elementary school students living in Aomori Prefecture. By investigating these relationships, we aimed to obtain clues to a healthy life.

The purpose of this study is to clarify the relationship amount of physical activity and lifestyle and self-esteem of elementary school students living in Aomori Prefecture.

\section{Methods}

\subsection{Subjects}

Ninety-one elementary school students in the 4th to 6th grade in A Town, Aomori Prefecture.

Aomori Prefecture, where the subjects live, is in the northern part of Japan and has heavy snowfall in winter. Town $\mathrm{A}$ is a rural town with a population of about 4000 , whose main industry is agriculture and fisheries. There is one public elementary school in the town.

\subsection{Survey Method}

The subjects were asked to wear the lifestyle-related recorder Life Coder GS ${ }^{\bullet}$ (Suzuken, Japan) for a total of four consecutive days, two weekdays and two holidays. Life Coder is a pedometer with a built-in accelerometer, which is attached to the abdomen to easily measure exercise intensity. Furthermore, information such as gender and physique, lifestyles (the way of commuting to school, 
time of watching television (TV), time of playing electronic games), self-esteem were acquired by a questionnaire. Survey period was June 2018. Regarding ethical consideration, the purpose and content of the research were explained to the subjects in writing and verbally, and the consent of the parents was obtained in writing. In addition, the approval of the ethics committee of the institution to which the researcher belongs was obtained.

\subsection{Survey Contents}

As definition of terms, the amount of physical activity in this study is 1) number of steps, 2) dose of exercises, and 3) exercise (EX) based on the data obtained from Life Coder GS., 4) the total amount of time during which subjects exercised strongly (strong activity time).

Regarding physical activities, data obtained from Life Coder GS are number of steps per day, dose of exercise (energy consumption by exercise and walking) (kcal), exercise (EX) which is added to the Mets conversion value, $1 \mathrm{EX}$ is equivalent to 20 minutes of normal walking, and 23 exercises per week are recommended for adults, activity time for each exercise intensity and strong activity time, the total of exercise time with fast walking or higher.

Concerning lifestyles and self-esteem, data obtained from the questionnaire were gender, grade, height, weight, means of go to school on weekdays, time spent watching TV or video, time spent playing electronic games by personal computer (PC), smartphone or game consoles, and self-esteem. Screen time was defined as the time spent using devices such as TV, PC, smartphones, and game consoles Regarding self-esteem, we asked for answers using a four-case method using a self-esteem measurement scale (Tokyo version) consisting of 22 items. As a subscale, it consists of 8 items of "self-evaluation/self-acceptance", 7 items of "self in a relationship", and 7 items of "self-assertion/self-determination". The higher the score means the higher the self-esteem.

\subsection{Analytical Method}

Data are expressed as mean \pm standard deviation. To compare various parameters (number of steps per day, dose of exercise, EX and strong activity time) by gender and presence or absence of obesity, data were analyzed by unpaired $\mathrm{t}$-test. Between weekdays and holidays differences in various parameters were assessed using paired t-test. The data was compared about the relationship between screen time, physical activity, and self-esteem using Pearson's correlation coefficient. $\mathrm{p}<0.05$ was considered significant.

\section{Results}

\subsection{Physique}

The degree of obesity was calculated using the Japanese age-specific obesity calculation formula [13] for elementary school children. $13.3 \%$ of students were classified as obese with a classification of obesity of $20 \%$ or higher (Table 1 ). 
Table 1. Percentage of obesity.

\begin{tabular}{ccccc}
\hline & Normal & Mild obesity & $\begin{array}{c}\text { Moderate } \\
\text { obesity }\end{array}$ & $\begin{array}{c}\text { Severe } \\
\text { obesity }\end{array}$ \\
\hline Degree of obesity & $-20 \%-+20 \%$ & $+20 \%-+30 \%$ & $+30 \%-+50 \%$ & $+50 \%$ \\
Boys $(\mathbf{n}=39)$ & 33 & 3 & 1 & 2 \\
Girls $(\mathbf{n}=51)$ & 45 & 4 & 0 & 2 \\
\hline
\end{tabular}

\subsection{Amount of Physical Activity}

This section describes the cases excluded from the analysis. Eleven children who did not have a pedometer record, those who took less than 1,500 steps on weekdays, and those who took less than 1,000 steps on holidays were excluded from the analysis because their activity may not have been measured accurately. The remaining forty-two subjects were analyzed. $11.9 \%$ of the 42 students were considered obese.

As comparison between boys and girls, the average daily number of steps for 4 days was 9,441 for boys and 10,475 for girls, and the results were slightly higher for girls in all surveyed items, but there was no significant difference.

Concerning comparison between weekdays and holidays, the average daily number of steps was 12,067 on weekdays, which was significantly higher than the 8,390 steps on holidays. The results also showed that weekday values were significantly higher than holidays in all other surveyed items.

Table 2 shows the amount of exercise on weekdays and holidays by gender.

About comparison by presence or absence of obesity, Table 3 shows a comparison of amount of physical activity between the non-obese group and obese group. The daily number of steps was 10,157 in the non-obese group and 10,756 in the obese group, showing that the number of steps, amount of exercise, EX and strong activity time were generally higher in the obese group, but there was no significant difference.

Regarding activity time by exercise intensity, Figure 1 shows a comparison of activity time by exercise intensity on weekdays and holidays. The time for fast walking was 26.5 minutes on weekdays, 16.7 minutes on holidays, and the time for jogging was 18.6 minutes on weekdays and 8.2 minutes on holidays, a significant difference. There was no difference by gender or classification of obesity.

\subsection{Lifestyles}

As to the way of commuting on weekdays, the most common way was by bus, with 22 people (56.4\%) on the first day and 19 people (45.2\%) on the second day. The number of children who went to school on foot was 8 (19.0\%) on the first day and 7 (16.7\%) on the second day. Comparing the amount of exercise in the case of using the bus and the case of going to school on foot, the number of steps and strong activity time were larger for those who went to school on foot, and the time for fast walking was significantly longer $(\mathrm{p}<0.01)$ (Table 4$)$. 
Table 2. Amount of physical activity by gender: Difference between weekdays and holidays (Mean $\pm \mathrm{SD})$.

\begin{tabular}{|c|c|c|c|}
\hline & Weekdays & Holidays & $p$ value \\
\hline \multicolumn{4}{|l|}{ Steps (/day) } \\
\hline Boys $(n=10)$ & $11,732 \pm 4170$ & $7149 \pm 3166$ & 0.039 \\
\hline Girls $(n=32)$ & $12,172 \pm 3028$ & $8778 \pm 3686$ & 0.000 \\
\hline \multicolumn{4}{|c|}{ EX (METs $\times$ hour/day) } \\
\hline Boys $(n=10)$ & $4.2 \pm 1.9$ & $1.9 \pm 1.1$ & 0.009 \\
\hline Girls $(n=32)$ & $4.2 \pm 1.5$ & $2.2 \pm 1.3$ & 0.000 \\
\hline \multicolumn{4}{|c|}{ Dose of exercise (kcal/day) } \\
\hline Boys $(n=10)$ & $248.9 \pm 113.8$ & $138.7 \pm 80.1$ & 0.018 \\
\hline Girls $(n=32)$ & $238.7 \pm 73.0$ & $156.5 \pm 76.1$ & 0.000 \\
\hline \multicolumn{4}{|c|}{ Strong activity time (minutes/day) } \\
\hline Boys $(n=10)$ & $43.7 \pm 18.5$ & $21.8 \pm 11.9$ & 0.014 \\
\hline Girls $(n=32)$ & $45.9 \pm 16.5$ & $29.5 \pm 24.3$ & 0.002 \\
\hline
\end{tabular}

Table 3. Amount of exercise: Difference between non-obesity and obesity (Mean \pm SD).

\begin{tabular}{ccc}
\hline & Non-obesity $(\mathbf{n}=\mathbf{3 7})$ & Obesity $(\mathbf{n}=\mathbf{5})$ \\
\hline Steps (/day) & $10,157 \pm 2800$ & $10,757 \pm 3067$ \\
EX (METs $\times$ hour/day) & $3.1 \pm 1.1$ & $3.5 \pm 1.6$ \\
Dose of exercise (kcal/day) & $190.5 \pm 66.8$ & $242.8 \pm 75.8$ \\
$\begin{array}{c}\text { Strong activity time (mi- } \\
\text { nutes/day) }\end{array}$ & $36.3 \pm 14.6$ & $38.8 \pm 15.9$ \\
\hline
\end{tabular}

Table 4. Comparison by the way of commuting (Mean $\pm \mathrm{SD}$ ).

\begin{tabular}{|c|c|c|c|}
\hline The way of commuting & On foot $(n=15)$ & By bus $(n=41)$ & $\mathrm{p}$ value \\
\hline Steps (/day) & $15,477 \pm 3623$ & $11,783 \pm 4230$ & 0.004 \\
\hline EX (METs $\times$ hour/day) & $6.0 \pm 2.3$ & $4.0 \pm 1.9$ & 0.002 \\
\hline $\begin{array}{c}\text { Dose of exercise } \\
\text { (kcal/day) }\end{array}$ & $304.1 \pm 112.5$ & $239.4 \pm 107.4$ & 0.054 \\
\hline $\begin{array}{l}\text { Strong activity time } \\
\text { (minutes/day) }\end{array}$ & $66.5 \pm 22.7$ & $42.3 \pm 18.5$ & 0.000 \\
\hline $\begin{array}{l}\text { Slowly walk time } \\
\text { (minute/day) }\end{array}$ & $74.0 \pm 22.1$ & $71.2 \pm 23.5$ & 0.693 \\
\hline $\begin{array}{l}\text { Fast walk time } \\
\text { (minute/day) }\end{array}$ & $41.9 \pm 13.4$ & $22.8 \pm 9.4$ & 0.000 \\
\hline Jogging (minute/day) & $24.6 \pm 13.7$ & $19.2 \pm 11.9$ & 0.152 \\
\hline
\end{tabular}


About screen time (TV time and game time), the average was calculated for the screen time. Weekdays TV time and game time were $101.9 \pm 78.8$ minutes and $52.6 \pm 53.0$ minutes, respectively, and holidays were $112.1 \pm 84.4$ minutes and $77.6 \pm 93.6$ minutes, respectively. Holiday screen times were significantly longer than those of weekdays ( $\mathrm{p}<0.01)$. (Figure 2 )

Regarding the self-esteem, cronbach $\alpha$, indicates the reliability of the scale, 0.882 for 8 items of "self-evaluation/self-acceptance", 0.848 for 7 items of "self in a relationship", and 0.874 for 7 items of "self-assertion/self-determination". The average per item is $3.15 \pm 0.42$ for boys and $3.09 \pm 0.77$ for girls in "selfevaluation/self-acceptance", $3.18 \pm 0.60$ for boys and $3.40 \pm 0.60$ for girls in "self in relationships", "self-assertion/self-determination" was $3.31 \pm 0.42$ for boys and $3.13 \pm 0.74$ for girls, showing no significant difference between boys and girls.

As for relationship between amount of exercise, living conditions, and selfesteem, the correlation coefficient between the number of steps on weekdays/holidays, the TV and game time on weekdays/holidays, and self-esteem was calculated.

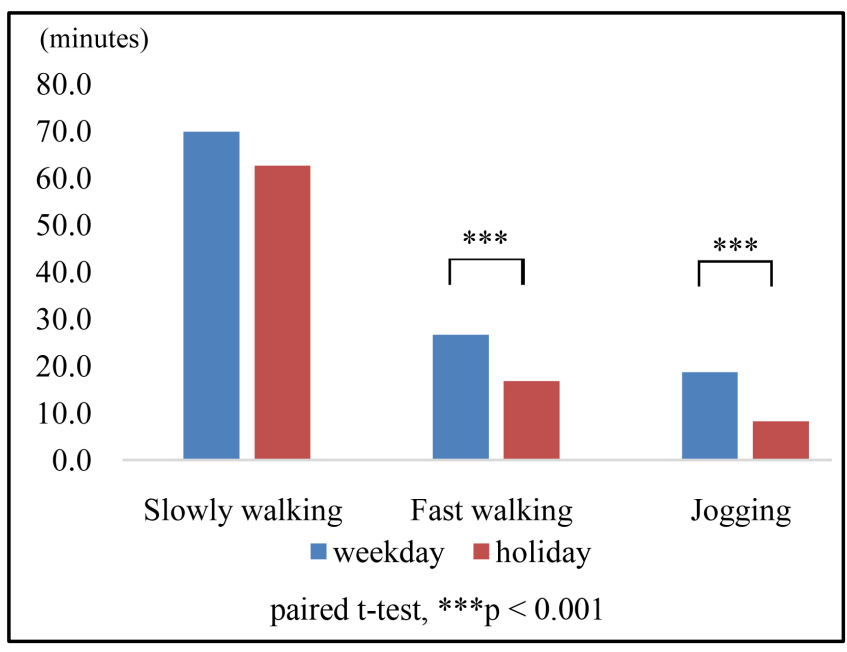

Figure 1. Strong activity time: Difference between weekdays and holidays $\left({ }^{* * *} \mathrm{p}<0.001\right)$.

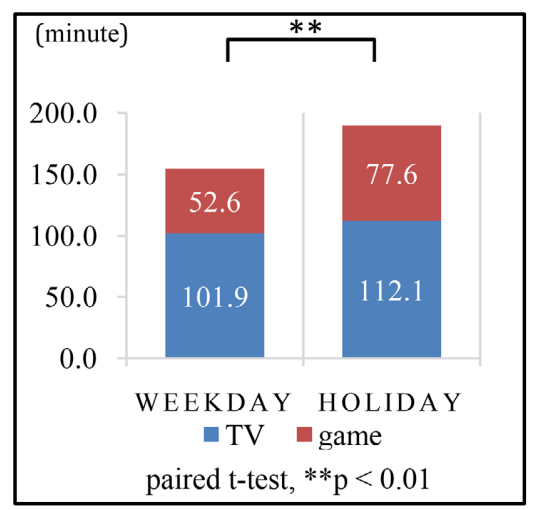

Figure 2. Comparison of screen time: Difference between weekdays and holidays. 
Table 5. Pearson's correlation coefficient between variables $\left({ }^{\star} \mathrm{p}<0.05,{ }^{\star *} \mathrm{p}<0.01\right)$.

\begin{tabular}{|c|c|c|c|c|c|c|c|}
\hline & $\begin{array}{c}\text { Steps } \\
\text { on weekday }\end{array}$ & $\begin{array}{l}\text { Steps on } \\
\text { holiday }\end{array}$ & $\begin{array}{l}\text { Screen time } \\
\text { on weekday }\end{array}$ & $\begin{array}{l}\text { Screen time } \\
\text { on holiday }\end{array}$ & $\begin{array}{l}\text { Self-evaluation/ } \\
\text { acceptance }\end{array}$ & $\begin{array}{l}\text { Self in a } \\
\text { relationship }\end{array}$ & $\begin{array}{l}\text { Self-assertion/ } \\
\text { determination }\end{array}$ \\
\hline Steps on weekday & 1 & $0.322^{*}$ & -0.006 & 0.088 & -0.018 & -0.161 & 0.026 \\
\hline Steps on holiday & & 1 & $-0.313^{\star}$ & $-0.320^{*}$ & 0.259 & 0.26 & $0.378^{\star}$ \\
\hline $\begin{array}{l}\text { Screen time on } \\
\text { weekday }\end{array}$ & & & 1 & $0.750^{\star *}$ & -0.167 & 0.173 & -0.266 \\
\hline $\begin{array}{l}\text { Screen time on hol- } \\
\text { iday }\end{array}$ & & & & 1 & -0.021 & 0.068 & -0.143 \\
\hline $\begin{array}{l}\text { Self-evaluation/ } \\
\text { acceptance }\end{array}$ & & & & & 1 & $0.583^{* *}$ & $0.842^{\star *}$ \\
\hline $\begin{array}{l}\text { Self in a } \\
\text { relationship }\end{array}$ & & & & & & 1 & $0.517^{\star *}$ \\
\hline $\begin{array}{l}\text { Self-assertion/ } \\
\text { determination }\end{array}$ & & & & & & & 1 \\
\hline
\end{tabular}

As a result, a significant negative correlation was found between the number of steps on holidays and the time spent watching TV games on weekdays and holidays. In addition, there was a significant positive correlation between the number of steps on holidays and the "self-assertion/self-determination" score of self-esteem (Table 5).

\section{Discussion}

The obesity rate of the subjects in this study was $13.3 \%$. The Japanese average is $8.63 \%$ for 9 -year-olds, $8.89 \%$ for 10 -year-olds, and $9.22 \%$ for 11 -year-olds [8], which is higher than that of children of the same age in Japan. However, the rate of obesity among children in Aomori Prefecture is $12.58 \%$ at age $9,11.73 \%$ at age 10 , and $10.84 \%$ at age 11 [8], so it can be said that the rate of childhood obesity in Aomori Prefecture is high.

Regarding the number of steps per day, the average on weekdays for boys was 11,732 steps and that for girls was 12,172 steps. It can be said that the number of steps of these subjects was small, because in a previous study showing the amount of activity of elementary school students in Japan, the daily number of steps was 14,000 - 18,000 for boys and 13,000 - 14,000 for girls [7]. Furthermore, according to the results of surveys performed with the same method in other municipalities in Aomori Prefecture from 2010 to 2013, the number of weekday steps for boys was $16,000-17,000$ and that for girls was $12,000-13,000$. The number of weekday steps taken by boys in this study was 11,732 and it was lower than that of the surrounding areas in the past studies. As a background to this, there is only one elementary school Town A, and many children come to school from afar. In a previous study it is said that the longer the commute distance, the more steps were taken [14], but the subject in this study included children used 
buses and private cars instead of walking. The result was that commuting on foot had significantly more steps and activity time than commuting by bus, and especially the time for fast walking was longer, so it can be said that to commute on foot had the effect of increasing moderate exercise. In other words, because the amount of activity is affected by the means of commuting to school, it was thought that even children commuting to school by bus or car would need to devise measures such as switching to walking even for only a part of the commuting route.

Furthermore, in this study, it was characteristic that boys took fewer steps than girls. However, it is generally said that boys take more steps than girls [7] [15]. Regarding this factor, according to the teachers at the school, dance activity was popular among girls during the survey period, and many girls danced during breaks between classes. In the latter half of elementary school, common pastimes with friends and peers of the same sex become more common. It was suggested that school recess and after-school activities are important for increasing the amount of exercise for school children. From the perspective of exercising while having fun, there are also efforts to try out athletic digital games [7]. Ideally, the amount of exercise naturally increases through playing and extracurricular activities.

Regarding the relationship between the degree of obesity and the amount of physical activity, previous studies have reported that the number of steps taken by obese children is less than that of children of standard body shape [7], but in our survey, the amount of exercise of obese children was not small. This is probably because the number of children targeted in this survey was small and it was not possible to make a sufficient statistical study.

Next, when comparing the amount of exercise on weekdays and holidays, the amount of activity in each item was significantly higher on weekdays. This is consistent with the results of previous studies [7] [16]. As for the activity time according to exercise intensity, on holidays, slow walking was performed in the same way as on weekdays, but exercise such as fast walking and jogging was significantly lower than on weekdays. From these facts, coming to school and receiving physical education provided a slightly stronger opportunity for exercise on weekdays, and those students were resting at home on holidays. We believe that this is also due to the influence of the family members with whom the children spend their holidays. Previous studies have shown that the exercise habits of fathers [17] and mothers [18] are related to the amount of exercise in young children. According to data from Aomori Prefecture, lack of exercise is mentioned as a health issue in adulthood, and more than $40 \%$ of children, regardless of age, spend their time watching TV, listening to music, or playing video games after school on weekdays, and the percentage increases as they get older [19]. From the results of this survey, there was a positive correlation between the screen times on weekdays and holidays, and the screen times on holidays were significantly longer than on weekdays, and the amount of activity such 
as the number of steps was small, so the way of spending at home affects the amount of exercise considerably. Since childhood is affected by the lifestyle of adults living with them, it is possible that improving the lifestyle of adults may lead to the health of children.

Finally, the subject's self-esteem was the same as or slightly higher than that of junior high school students in the same area [20] or the same grade survey [21] in Tokyo. Compared to other countries, young people in Japan are less likely to think of themselves positively [22] and begin to decline from elementary school to junior high school [23]. There are many studies that exercise has a positive effect on self-esteem [11] [12], but in this study, the factors of "self-assertion/ self-determination" that constitutes self-esteem had a positive correlation with the number of steps taken on holidays and a negative correlation with the screen time. While watching TV and games is a passive activity, many holiday sports and exercises are voluntary, so they might be related to self-assertion and selfdetermination factors that are part of the child's self-esteem. It is said that children who often engage in sports and other activities with their families tend to have high self-esteem [24], suggesting that how they spend their holidays with their families may affect their self-esteem.

\section{Limitation}

As a limitation of this study, about half of the elementary school students who participated in the survey were excluded from the analysis because they forgot to wear the device or did not wear it correctly. This may have caused a bias in the subjects. In the future, it will be necessary to improve the method of explanation and so that all subjects can measure easily and accurately.

\section{Conclusions}

As a result of investigating the amount of physical exercise of elementary school students in A town, Aomori Prefecture in June 2018, the following points were clarified.

1) The amount of exercise such as the number of steps was significantly higher on weekdays than on holidays.

2) No significant difference was found between boys and girls and the presence or absence of obesity.

3) The amount of activity on holidays was correlated with self-assertion/ determination of self-esteem.

Health-relates promotions are needed so that the entire community, including family and friends, can develop healthy habits.

\section{Acknowledgements}

We would like to express our gratitude to all the children, parents, and school staff for their cooperation in this research. 


\section{Declaration of Conflicting Interests}

All authors have no conflicts of interests directly relevant to the content of this article.

\section{References}

[1] Kumar, S. and Kell, A.S. (2017) Review of Childhood Obesity: From Epidemiology, Etiology, and Comorbidities to Clinical Assessment and Treatment. Mayo Clinic Proceedings, 92, 251-265. https://doi.org/10.1016/j.mayocp.2016.09.017

[2] Minowa, T., Tachihara, K. and Ostuka, K. (1996) Obesity and Lean Tendency Survey Results of Children in Kashima Town, Ibaraki Prefecture-Changes over the Past 10 Years. The Journal of Child Health, 55, 403-409.

[3] Kinugasa, A. (1995) Infant Obesity, Early Child Obesity, School Child Obesity, Adolescent Obesity. Pediatric Practice, 58, 1919-1925.

[4] Onodera, T., Kanda, A., Watanabe, Y., Ho, K. and Kawaguchi, T. (1998) Epidemiological Study on the Relationship between Childhood Obesity and Living Behavior. Japanese Journal of Health Education and Promotion, 6, 1-12.

[5] Kimura, Y., Yukizane, S. and Yamashita, F. (1987) Childhood Simplicity Obesity. Pediatric Medicine, 20, 730-743.

[6] Mossberg, H.O. (1989) 40-Year Follow-Up Overweight Children. The Lancet, 334, 491-493. https://doi.org/10.1016/S0140-6736(89)92098-9

[7] Togashi, K. (2012) Treatment of Obesity Exercise Guidance. Pediatrics Lecture, 3, 1118-1124.

[8] The National Statistics Center in Japan (2018) School Health Statistics Survey in 2017.

https://www.e-stat.go.jp/stat-search/files?page=1\&layout=datalist \&toukei=0040000 2\&tstat $=000001011648 \&$ cycle $=0 \&$ tclass $1=000001113655 \&$ tclass $2=000001113657 \&$ tc $\underline{\text { lass } 3 \mathrm{val}=0}$

[9] Ministry of Health, Labour and Welfare in Japan. Overview of Life Tables by Prefecture in 2015. https://www.mhlw.go.jp/toukei/saikin/hw/life/tdfk15/index.html

[10] French, S.A., Story, M. and Perry, C.L. (1995) Self-Esteem and Obesity in Children and Adolescents: A Literature Review. Obesity Research, 3, 479-490. https://doi.org/10.1002/j.1550-8528.1995.tb00179.x

[11] Ekeland, E., Heian, F., Hagen, K.B., Abbott, J. and Nordheim, L. (2004) Exercise to Improve Self-Esteem in Children and Young People. Cochrane Database of Systematic Reviews. https://doi.org/10.1002/14651858.CD003683.pub2

[12] Griffiths, L.J., Parsons, T.J. and Hill, A.J. (2012) Self-Esteem and Quality of Life in Obese Children and Adolescents: A Systematic Review. International Journal of Pediatric Obesity, 5, 282-304.

[13] Murata, M. (2018) Transition of Physical Evaluation of School Medical Examinations in Japan and Utilization of Growth Curve. Journal of Japanese Society of Growth, 24, 7-22.

[14] Nagai, Y. and Kimura, M. (1998) Physical Activity of Sixth Graders (Comparison between Two Urban Elementary Schools with Different Commuting Distances). Physical Fitness Science, 47, 911.

[15] Hamasaki, H. Aoto, K., Akataki, C., Shimomura, M., Masuda, H., Ono, K. and Nohara, R. (2001) Average Number of Steps, Body Fat Percentage and BMI by Grade for Children in Kyoto City. Physical Fitness Science, 50, 878. 
[16] Yoshida, Y. Hatakeyama, Y., Kikuchi, K., Miya, S., Endo, T. and Tatsumi, M. (1997) Health Guidance for Obese Children at School (3rd Report)-Using a Pedometer. Iwate Prefecture Public Health Magazine, 8, 52-53

[17] Moore, L.L., Lombardi, D.A., White, M.J., Campbell, J.L., Olivia, S.A. and Ellison, R.C. (1991) Influence of Parents' Physical Activity Levels on Activity Levels of Young Children. The Journal of Pediatrics, 118, 215-219. https://doi.org/10.1016/S0022-3476(05)80485-8

[18] Okugawa, T. Hashimoto, S., Ino, H., Uemura, T., Sakakibara, S., Kinoshita, S., Usuta, T., et al. (1998) Relationship between Exercise Evaluation and Lifestyle of Rural Infants Using a Pedometer. Pediatric Practice, 61, 1788-1791.

[19] Aomori Prefectural Board of Education (2012) To Live a Healthy and Lively Life for a Lifetime. Children's Healthy Life Promotion Project for the Future. Supplementary Reader about Health.

https://www.pref.aomori.lg.jp/bunka/education/kenkoufukudokuhon.html

[20] Hiroya, Y. (2018) Guidance for Fostering Self-Esteem of Junior High School Students through the Creation and Practice of a Program to Create a Place for Students. Aomori Prefectural General School Education Center.

http://kenkyu.edu-c.pref.aomori.jp/?action=common download main\&upload $\mathrm{id}=$ $\underline{600}$

[21] Faculty and Staff Training Center in Tokyo (2020) Research on Self-Esteem and Self-Affirmation (1st Year)-Aiming to Develop a Lesson Model for Each School Type. Bulletin of Tokyo Faculty and Staff Training Center, 20, 36-62. https://www.kyoiku-kensyu.metro.tokyo.lg.jp/09seika/reports/files/bulletin/r2/mate rials/r2 20 03.pdf

[22] Cabinet Office in Japan (2014) Survey on Youth Consciousness in Japan and Other Countries in 2013.

https://www8.cao.go.jp/youth/kenkyu/thinking/h25/pdf index.html

[23] Aomori Prefecture (2015) Annual Report on Children and Youth in Aomori Prefecture.

https://www.pref.aomori.lg.jp/soshiki/kankyo/seishonen/seisyounen-kisotyousa.ht $\underline{\mathrm{ml}}$

[24] Faculty and Staff Training Center in Tokyo (2011) The Question and Answer to Enhance Self-Esteem and Self-Affirmation of Children. Bulletin of Tokyo Faculty and Staff Training Center, 11, 6-26.

https://www.kyoiku-kensyu.metro.tokyo.lg.jp/09seika/reports/files/bulletin/h23/ma terials/h23 mat01a 01.pdf 